\title{
Identifying nursing research priorities in Vietnam: a modified Delphi study ${ }^{\dagger}$
}

Yupin Aungsurocha,*, Xuan Ha Thi Nhü, Tran Thuy Khanh Linh ${ }^{b}$, Rapin Polsook Rungrawee Navicharerna, Joko Gunawan ${ }^{a}$

${ }^{a}$ Faculty of Nursing, Chulalongkorn University, Pathumwan, Bangkok 10330, Thailand

${ }^{b}$ Faculty of Nursing and Medical Technology, University of Medicine and Pharmacy, Ho Chi Minh, Dong Nai 70000, Vietnam

Received: 25 April 2019; Accepted: 2 July 2019; Published: 20 December 2019

Abstract: 0 objective: There is no single study that has examined nursing research priorities in Vietnam. This study aimed to gain consensus from experts on the nursing research priorities in Vietnam.

Methods: A three-round modified Delphi study was used in this study. A focus group discussion among experts was conducted in round I to identify the nursing research priorities $(n=23)$. Data in round I were analyzed using content analysis. In round II, participants were invited to rate the importance of each nursing priority topic in a 5-point Likert scale questionnaire, which had a $74 \%(n=17)$ response rate. In round III, the questionnaire was returned to the experts $(n=17)$ until consensus was reached. Data from round II and round III were analyzed to produce mean score and final rank.

Results: The top 12 research priority lists were identified, which included subthemes and areas of possible investigations. All priorities were classified into three groups in the rank order, namely: (i) nursing management and leadership, which included (1) nursing care quality, (2) management and leadership of nurse managers, (3) nursing image, (4) professional nurse competency, and (5) human resource management; (ii) nursing education, which included (1) knowledge-specific domain, (2) the linkage between education and practice, and (3) nurse teacher workforce; and (iii) nursing service, which included (1) adult nursing concern, (2) patient safety, (3) public health nursing concern, and (4) quality of life of patients and nurses.

Conclusions: Consensus among experts was achiever, and the findings are considered as the basis of resources to the most essential research needs in Vietnam.

Keywords: Delphi method $\bullet$ research priorities • nursing • Vietnam

(c) Shanxi Medical Periodical Press.

${ }^{\dagger}$ This project was supported by ASEAN Studies Center of Chulalongkorn University, Bangkok, Thailand. The project name is International Nursing Networking and Collaborative Research beyond AEC 2015 (No. 15410170300040).

How to cite this article: Aungsuroch Y, Ha TNX, Tran TKL, Polsook R, Navicharern R, Gunawan J. Identifying nursing research priorities in Vietnam: a modified Delphi study. Front Nurs. 2019; 4: 249-260. 


\section{Introduction}

Nursing discipline has a responsibility to generate sound research to support best patient care with evidence-based standard and to demonstrate the efficacy of contemporary practice. Nursing research has been developed in recent years in Vietnam as a result of master degree in nursing workshops on nursing research organized by Vietnam Nurses Association (VNA) and hospitals. ${ }^{1}$ However, nurses are demanded to understand both the national context of research and the strong and viable long-term research capacity. ${ }^{2}$

Nationally agreed research priority setting is considered as the critical strategy for the development of nursing science ${ }^{3}$ and brings new insights of key stakeholders to come to a consensus as to the gaps in the science that need to be filled. ${ }^{4}$ Nursing research priority is dynamic in response to the stage of nursing development, and can be used by faculty, students, and nurse scholars to design focused research plans, efforts, and investments for the best outcomes in the community. ${ }^{2}$

Identifying and setting nursing research priorities has been popular internationally and serves multiple purposes. Several countries have developed research agenda to guide their research programs, which fit with the ongoing context of health care system today in areas as diverse as home health care nursing, public health nursing, nursing education, mental health nursing, oncology nursing, clinical nursing, pediatric nursing, and nursing informatics. ${ }^{4-6}$ However, in Vietnam, there are no previous studies focusing on the identification of research priorities in the nursing context. Thus, this study aimed to identify nursing research priorities as perceived by nurse managers, nurse educators, and clinical nurses. This study represents a significant step in building the significant development in nursing in the country.

\subsection{Nursing education in Vietnam}

Nursing education system in Vietnam has been developed over the last 20 years. $^{7}$ There are four main nursing programs, namely, bachelor nursing program, 2-year diploma program, 3-years diploma program, and master of nursing science program. ${ }^{1,7}$ In spite of variety of these nursing education programs, there is still no unified standardization of curriculum among them. However, the nursing education programs in Vietnam have been accredited by the Ministry of Health and the Ministry of Education and Training following ASEAN University Network-Quality Assurance
(AUN-QA) to ensure the quality of the teachers and the students. ${ }^{8}$

Currently, 10 national universities primarily offer four-year bachelor programs, eight of the 10 universities offer master of nursing science programs, and the other nursing programs are offered by the other universities or colleges at the provincial level. ${ }^{9}$ Institutions in Vietnam cooperate with international institutions from Philippine, Thailand, Taiwan, and USA to conduct and run the master of nursing science program. Currently, approximately $\mathbf{2 0 0}$ master nurses are graduated in one year. ${ }^{9}$ However, this number remains low seen from the need of the country.

Until today, there has been no Doctor of Philosophy in Nursing program in Vietnam. Most of them should go to other countries to pursue the doctoral degree. Currently, the number of $\mathrm{PhD}$ programs in nursing is less than 10 in Vietnam. The Doctor of Philosophy of Nursing Science program is expected to open by 2020 , as is the most important concern in the country. ${ }^{9}$

In regards to the research development, although it is required to conduct a research for students in bachelor's and master's program, however, it remains slow and needs an improvement. The competencies of faculty members in doing research also need to be advanced. To increase the number of research, all faculty members are required to conduct a research every year.

\subsection{Nursing service in Vietnam}

In line with the healthcare system development today, Vietnamese nurses are continuously learning and improving their nursing practice. However, the quality of nursing care still needs improvement to meet the patients' needs. Today, Vietnam is facing nursing shortage, with 11.7 nurses per 10,000 inhabitants. ${ }^{10}$ The number of nurses in rural and urban areas is unequal. In hospitals, the ratio of nurses and patients is also very low, where one nurse cares for 20 or 30 patients. ${ }^{1,9}$ Nurses are working in 12-hour shift, and even sometimes 24-hour shift, which brings so much pressure among them. Limited facilities and poor working conditions are also still remarked. ${ }^{10}$ Unfortunately, a large number of nurses $(70 \%)$ are holding secondary level qualification, which mainly focuses on medical techniques and is task oriented. As a consequence, the care quality is questionable. ${ }^{11}$ The research is conducted only on an individual basis, particularly for the head nurses who hold bachelor's or master's degree in nursing. Some hospitals have been emphasizing their nurses to conduct a research and present the results in their own hospitals. 


\subsection{Nursing association in Vietnam}

There is no nursing council yet in Vietnam; thus, the VNA and the Vietnam Nursing Teacher Branch are playing key roles in providing the nursing voice and image. However, the Ministry of Health and Ministry of Education and Training are responsible for developing nursing policy, promoting quality and quantity of nurses as well as granting a certificate for nursing practice. .-11 $^{9-1}$ The VNA is spreading around Vietnam, which is mainly a professional institution that provides research training for all levels of nurses. Until today, VNA has been trying to improve the quality of nursing care and the competency of nurses. ${ }^{1}$ However, there is no nursing agenda developed for Vietnam yet, which is therefore this study can be an input for VNA to direct nursing research and enhance collaboration among nurses in the region.

\section{Methods}

\subsection{Study design}

A modified Delphi method was used in this study to determine research priorities. The Delphi research method has been widely used to generate ideas in nursing and in other disciplines. ${ }^{12}$ This method is a structured process with a series of rounds from a panel of experts or informants to seek their opinions and judgments on a particular issue and to discuss the agreed consensus to minimize the bias. ${ }^{12}$ Although there is no specific number of rounds in this method, however, in this study, we used three rounds to reach consensus among experts, as suggested by Hasson et al. ${ }^{12}$ We used this method because it allows anonymity and eliminates the potential of bias from the dominant experts among participants. ${ }^{13}$ In round I, responses from experts were summarized and analyzed, and a new questionnaire was developed in round II based on the results from round $I$ and then sent back to each expert to provide a response. In round III, the same questionnaire was returned again to each expert until consensus was reached. In round II and round III, the questionnaire was administered electronically and individually, and in rounds, participants had the option of changing their mind after considering the group opinion. The study was conducted from December 2016 to May 2017.

\subsection{Study participants}

Participants in this study were selected using purposive sampling. In round I, 23 participants were purposively selected. In round II, all 23 participants were re-invited again, but only 17 participants responded. In round III, only 17 participants from round II remained (100\%). There is no such agreement on the sample size for a Delphi study ${ }^{14}$; however, many published Delphi studies have samples from 10 to 100 or more. ${ }^{15}$ The participants were directors of nursing, nurse managers (all grades), clinical nurse specialists, clinical nurse facilitators, healthcare providers, staff nurses, and other heath stakeholders who were closely involved in all levels of health services. All experts were chosen based on their management and clinical experiences in the nursing arena and their publications in various nursing topics. To represent Vietnam, the participants from public and private hospitals were recruited, as they would be able to provide relevant information in regard to nursing research priorities in different settings.

\subsection{Procedures}

In round I, the 23 participants were asked to list research priorities based on their expertise, observation, needs, and clinical experience in nursing education, nursing management, and nursing service. After all topics were written by all participants, the principle investigators asked each participant why they chose the topics in focus group discussion among participants.

In round II, participants presented the results of priorities in round I in a questionnaire format, and they were invited to rate the importance of each priority on a 5-point Likert scale, which ranged from 1 to 5 (1=unimportant, 2=little important, 3=moderately important, 4=important; and $5=$ very important), by online or mail system. Seventeen participants were requested to provide response to the questionnaire and rate the research priorities (see Table 1). The delay between round I and round II was one month.

In round III, the questionnaire with the mean score of each research priority based on the results of round II was circulated again to 17 participants, and they were invited to respond to the questionnaire. There was no different format and layout between questionnaires in round II and round III. The objective was to gain a final consensus on the research priorities. There was a two weeks delay between round II and round III. In this round, we provided two options before rating the questionnaire, namely, (i) agree with the results and no need to rate the questionnaire and (ii) disagree and continue rating. All participants (100\%) agreed with the results, and there was no need to change and rate each item. We ensured that all research topic priorities had been confirmed by all participants. 


\begin{tabular}{lccc}
\hline Demographic information & $f$ & $\%$ & $M \pm S D$ \\
\hline \hline Age (years) & 3 & 17.6 & \\
$20-29$ & 11 & 64.7 & \\
$30-39$ & 2 & 11.8 & \\
$40-49$ & 1 & 5.9 & \\
$50-59$ & & & \\
Gender & 14 & 82.4 & \\
Female & 3 & 17.6 & \\
Male & & & \\
Area of employment & 6 & 35.3 & \\
$\quad$ Surgical areas & 3 & 17.6 & \\
Medical areas & 8 & 47.1 & \\
$\quad$ Nursing administration/hospital policy & & & \\
Job classification & 2 & 11.8 & \\
$\quad$ Registered nurse/midwife & 3 & 17.6 & \\
Senior registered nurse & 6 & 35.3 & \\
Nursing administrator & 6 & 35.3 & \\
$\quad$ Nursing teacher/educator & & & \\
Educational background & 6 & 35.3 & \\
$\quad$ Bachelor of nursing science & 11 & 64.7 & \\
Master of nursing science & & & \\
Year of experience in nursing & & & $7.18 \pm 0.12$ \\
Year of experience in current position & & & \\
\hline
\end{tabular}

Note: M: mean; SD: standard deviation.

Table 1. Characteristics of respondents in round II and round III $(n=17)$.

\subsection{Data analysis}

To analyze data of round I, first, we performed a summative content analysis using lists of priorities written by all participants, in which word frequency counts for each identified term were calculated. ${ }^{16}$ Although there was no standard for what frequencies of each term should exist, we decided to put the highest frequency as the highest priority. Second, we used a thematic content analysis outlined by Krippendorff, ${ }^{17}$ in which all statements from participants during focus group discussion were transcribed and coded individually by the researchers, who then met to reexamine the priorities and consensus was reached on the key themes that emerged. Third, we combined the results of the summative and thematic content analysis to identify themes and subthemes and to help structure the subsequent questionnaires for rounds II and III.

The data from round II and round III were analyzed using descriptive statistics to produce a mean score and standard of deviation. Using a mean value in collapsing the responses has been used in numerous Delphi studies with ranking the mean value considered as a typical method in prioritization. ${ }^{18}$

\section{Results}

Round I involved a written method to list research topic priorities in nursing, which were then discussed among participants. Twenty-three respondents were involved in this round, identifying 140 research topics, which were then analyzed by the authors using a summative and thematic content analysis to compare and contrast among the topics. As a result, the top 12 research priority lists were identified, which included subthemes and areas of possible investigation. All priorities were grouped into three categories, namely: (i) nursing management and leadership (nursing care quality, professional nurse competency, management leadership of nurse managers, human resource management (HRM), and nursing image); (ii) nursing education (the linkage between education and practice, knowledge-specific domain, and nurse teacher workforce); and (iii) nursing service (patient safety, quality of life [QoL], public health concern, and adult nursing concern).

In round II, the 12 research priority lists that emerged from round I were sent to the respondents. Participants were invited to rate research priorities on a 5-point Likert scale, ranging from 1 to 5 (1=unimportant, 2=little important, 3=moderately important, 4=important, and 5=very important). The higher mean score from each theme and subtheme indicated more important research topic priority.

As shown in the Table 2, the rating results from round II were grouped into the following themes: (i) In the nursing management and leadership category, the research topic of nursing care quality was the first priority in Vietnam, which consisted of job description of nurses $(M \pm S D)(4.53 \pm 0.62)$, standard of nursing care $(4.50 \pm 0.09)$, evidence-based practice (EBP) $(4.43 \pm 0.04)$, nursing care delivery $(4.29 \pm 0.01)$, innovation in nursing practice $(4.26 \pm 0.42)$, nursing documentation $(4.14 \pm 0.20)$, and nurse attitude and awareness toward quality $(4.12 \pm 0.70)$. The lowest research priority was HRM $(3.96 \pm 0.14)$, including nurse career (4.05 \pm 0.11$)$, continuing professional development (CPD) (3.94 \pm 0.04$)$, work motivation (3.94 \pm 01.25$)$, and nurse staff recruitment $(3.82 \pm 0.88)$. (ii) In the nursing education theme, the knowledge-specific domain was the highest priority related to the quality of teaching learning (4.63 \pm 0.01$)$, followed by the linkage between education and practice $(4.53 \pm 0.06)$ in regard to the curriculum model (4.65 \pm 0.61$)$, learning outcome $(4.53 \pm 0.62)$, and education model $(4.41 \pm 0.71)$, and the nurse teacher workforce $(4 \pm 0.04)$ associated with teacher-student ratio (4.06 \pm 01.03$)$ and faculty competency (3.94 \pm 0.97$)$. (iii) In the nursing service theme, the highest priority was in the adult nursing concern $(4.29 \pm 0.07)$, which was related to wound care management $(4.41 \pm 0.71)$, pain 


\begin{tabular}{lll}
\hline Category & & Subcategory \\
\hline \hline Nursing & Nursing & Job description of \\
management & care quality & nurses $(4.53 \pm 0.62)$ \\
and leadership & $(4.37 \pm 0.12)$ & Standard of nursing \\
& & care $(4.50 \pm 0.09)$
\end{tabular}

Evidence-based practice $(4.43 \pm 0.04)$

Nursing care delivery $(4.29 \pm 0.01)$

Innovation in nursing practice $(4.26 \pm 0.42)$

Nursing documentation

$(4.14 \pm 0.20)$

Nurse attitude and awareness toward quality $(4.12 \pm 0.70)$

Management and leadership of nurse managers $(4.36 \pm 0.15)$

Quality of leadership and management $(4.38 \pm 0.20)$

Supervision (4.35 \pm 0.14$)$

Nursing image $(4.21 \pm 0.17)$

Professional nurse competency $(4.16 \pm 0.03)$

\section{Human} resource management $(3.96 \pm 0.14)$

$\begin{array}{lll}\begin{array}{l}\text { Nursing } \\ \text { education }\end{array} & \begin{array}{l}\text { Knowledge- } \\ \text { specific } \\ \text { domain } \\ (4.63 \pm 0.01)\end{array} & \begin{array}{l}\text { Quality of teaching } \\ \text { learning }(4.63 \pm 0.01)\end{array} \\ \begin{array}{l}\text { The linkage } \\ \text { between } \\ \text { education } \\ \text { and practice }\end{array} & \begin{array}{l}\text { Curriculum model } \\ (4.65 \pm 0.61)\end{array} \\ & \text { Learning outcome } \\ (4.53 \pm 0.06) & \text { Education model } \\ & (4.41 \pm 0.71) \\ & \text { Nurse teacher } & \text { Teacher-student ratio } \\ \text { workforce } & (4.06 \pm 1.03) \\ (4 \pm 0.04) & \text { Faculty competency } \\ & & (3.94 \pm 0.97)\end{array}$
image $(4.21 \pm 0.17)$

Standard competency of nurses $(4.16 \pm 0.03)$

Work motivation for staff nurses $(3.94 \pm 1.25)$

Recruitment of nurse staff $(3.82 \pm 0.88)$
Possible investigation

$M \quad S D$

Clarifying job description of nurses with different backgrounds

4.53

of nurses

$\begin{array}{lll}\text { Developing and updating nursing care standard } & 4.76 & 0.44\end{array}$

$\begin{array}{lll}\text { Developing nursing care standard for common diseases in } & 4.59 & 0.71\end{array}$ specific nursing area

$\begin{array}{lll}\text { Evaluating nursing outcome } & 4.47 & 0.62\end{array}$

$\begin{array}{lll}\text { Setting goals of nursing care } & 4.35 & 0.61\end{array}$

$\begin{array}{lll}\text { Evaluating the effectiveness and efficiency of nursing care } & 4.35 & 0.61\end{array}$

$\begin{array}{lll}\text { Applying evidence based on nursing practice } & 4.59 & 0.62\end{array}$

$\begin{array}{llll}\text { Increasing nursing research skills and knowledge for staff nurse } & 4.41 & 0.62\end{array}$

$\begin{array}{lll}\text { Identifying nurse awareness of roles in nursing research } & 4.29 & 0.69\end{array}$

$\begin{array}{lll}\text { Identifying nurse:patient ratio and its effect on quality of nursing } & 4.41 & 0.62\end{array}$

care

$\begin{array}{llll}\text { Model of nursing care delivery (effect on nursing care quality) } & 4.18 & 0.64\end{array}$

$\begin{array}{lll}\text { Integrating technology in nursing practice } & 4.29 & 0.69\end{array}$

$\begin{array}{lll}\text { Attitude of nurses toward the use of technology } & 4.23 & 0.75\end{array}$

$\begin{array}{lll}\text { Nurse attitude toward nursing documentation } & 4.23 & 0.75\end{array}$

$\begin{array}{lll}\text { Identifying the quality of nursing documentation in the nursing } & 4.06 & 1.03\end{array}$

process

$\begin{array}{lll}\text { Evaluating the nurse attitude, awareness, and compliance } & 4.12 & 0.70\end{array}$

toward nursing standard and care quality

$\begin{array}{lll}\text { Evaluating the quality of leadership and management of nurse } & 4.53 & 0.62\end{array}$

managers

$\begin{array}{lll}\text { Evaluating the leadership styles of nurse managers } & 4.23 & 0.9\end{array}$

$\begin{array}{lll}\text { Evaluating nurse manager supervision model } & 4.41 & 0.94\end{array}$

$\begin{array}{llll}\text { Developing key performance indicator for supervising nurse staff } & 4.29 & 0.92\end{array}$

$\begin{array}{lll}\text { Perception of community on professional nursing image } & 4.29 & 0.69\end{array}$

$\begin{array}{lll}\text { Perception of nurses and other health professionals on nursing } & 4.12 & 0.93\end{array}$

image

Identifying factors influencing professional nurse competency

Providing intervention to increase nurse competency

Developing standard of nurse competency for different

professional nurse competency levels - mixed level

Measuring and evaluating nurse competence (skill, knowledge, attitude), behavior and performance, and decision-making

Nurse satisfaction about nursing career

Evaluating clinical ladder of nurses

Evaluating the process of continuing professional development of staff nurse

Identifying factors influencing the intention of nurses to join training, course, and education

Identifying factors influencing work motivation of nurses, such as salary and working environment

Evaluating the recruitment process of new staff nurses

Developing and evaluating teaching learning approaches that relate to evidenced-based practice

Evaluating nursing student practice in the laboratory Identifying the effectiveness of the quality of teaching learning Evaluating curriculum models for professional education

$\begin{array}{ll}3.82 & 0.88 \\ 4.65 & 0.49 \\ 4.65 & 0.49 \\ 4.59 & 0.51 \\ 4.65 & 0.61 \\ 4.53 & 0.62 \\ 4.41 & 0.71 \\ 4.06 & 1.03 \\ 3.94 & 0.97\end{array}$

\section{Measuring learning outcome}

Identifying and evaluating education model focusing on delivery of patient-centered care

Examining the impact of the teacher-student ratio on the learning outcome

Identifying creative approaches to enhance nursing faculty competency 


\begin{tabular}{|c|c|c|c|c|c|}
\hline Category & & Subcategory & Possible investigation & M & SD \\
\hline \multirow[t]{15}{*}{ Nursing service } & \multirow[t]{3}{*}{$\begin{array}{l}\text { Adult nursing } \\
\text { concern } \\
(4.29 \pm 0.07)\end{array}$} & $\begin{array}{l}\text { Wound care } \\
\text { management } \\
(4.41 \pm 0.71)\end{array}$ & Wound care management & 4.41 & 0.71 \\
\hline & & $\begin{array}{l}\text { Pain management } \\
(4.29 \pm 0.85)\end{array}$ & Pain management & 4.29 & 0.85 \\
\hline & & $\begin{array}{l}\text { Management of end- } \\
\text { of-life or palliative care } \\
(4.18 \pm 0.81)\end{array}$ & Management of end-of-life or palliative care & 4.18 & 0.81 \\
\hline & \multirow{2}{*}{$\begin{array}{l}\text { Patient safety } \\
(4.29 \pm 0.14)\end{array}$} & \multirow{2}{*}{$\begin{array}{l}\text { Nursing-sensitive } \\
\text { indicator }(4.29 \pm 0.14)\end{array}$} & Developing nursing-sensitive indicator standard & 4.29 & 1.05 \\
\hline & & & $\begin{array}{l}\text { Evaluating nursing-sensitive outcome indicators ("prevalence of } \\
\text { pressure ulcer", "falls and falls with injury", "nosocomial selective } \\
\text { infection", "nosocomial urinary tract infection", "medication error", } \\
\text { "pneumonia", "vein system complication", "failure to rescue", } \\
\text { "restraint", "sepsis", "gastrointestinal bleeding", and "shock"). } \\
\text { Patient-related perception included "patient/family satisfaction } \\
\text { with nursing care" and "patient/family satisfaction with pain } \\
\text { management". Patient-related use of health care included "length } \\
\text { of stay", "waiting time of nursing care", and "unplanned hospital } \\
\text { visits post discharge". Patient-related functional status included } \\
\text { "vital sign status" and "self-care ability" }\end{array}$ & 4.29 & 0.85 \\
\hline & \multirow{6}{*}{$\begin{array}{l}\text { Public health } \\
\text { nursing } \\
\text { concern } \\
(4.25 \pm 0.09)\end{array}$} & \multirow{2}{*}{$\begin{array}{l}\text { Community strategies } \\
\text { to reduce health risks } \\
(4.41 \pm 0.06)\end{array}$} & Early detection of disease & 4.41 & 0.62 \\
\hline & & & Developing strategies/intervention to reduce health risks & 4.41 & 0.71 \\
\hline & & $\begin{array}{l}\text { Family care, } \\
\text { caregiving, and } \\
\text { preventive mental } \\
\text { health }(4.18 \pm 0.64)\end{array}$ & - & 4.18 & 0.64 \\
\hline & & \multirow{3}{*}{$\begin{array}{l}\text { Culturally appropriate } \\
\text { lifestyle intervention } \\
\text { for health promotion, } \\
\text { primary and } \\
\text { secondary prevention, } \\
\text { risk reduction, and } \\
\text { health-seeking } \\
\text { behavior across the } \\
\text { lifespan }(4.17 \pm 0.08)\end{array}$} & Models of self-care for patients with chronic diseases & 4.29 & 0.69 \\
\hline & & & Identifying the effectiveness of nursing home care & 4.17 & 0.81 \\
\hline & & & $\begin{array}{l}\text { Developing and evaluating rehabilitation programs for patients } \\
\text { with chronic diseases in the community }\end{array}$ & 4.06 & 0.83 \\
\hline & \multirow{4}{*}{$\begin{array}{l}\text { Quality of life } \\
(4.13 \pm 0.14)\end{array}$} & \multirow{2}{*}{$\begin{array}{l}\text { Quality of life of } \\
\text { patients }(4.18 \pm 0.02)\end{array}$} & Patient satisfaction of nursing services & 4.23 & 0.75 \\
\hline & & & $\begin{array}{l}\text { Identifying the quality of life of patients, especially patients with } \\
\text { chronic diseases }\end{array}$ & 4.12 & 0.78 \\
\hline & & \multirow[t]{2}{*}{$\begin{array}{l}\text { Quality of working life } \\
\text { of nurses }(4.09 \pm 0.11)\end{array}$} & $\begin{array}{l}\text { Working stress environment and the impact on nursing } \\
\text { performance }\end{array}$ & 4.12 & 1.05 \\
\hline & & & Identifying quality of life of nurses & 4.06 & 0.9 \\
\hline
\end{tabular}

Note: All topics for possible investigation can be done with any kind of designs. M: mean; SD: standard deviation.

Table 2. Research topic priorities in Vietnam.

management $(4.29 \pm 0.85)$, and end-of-life or palliative care management $(4.18 \pm 0.81)$. The lowest priority was in the QoL of patients and nurses (4.13 \pm 0.14$)$. However, we emphasized that all themes can be studied in any types of designs with all possible investigations indicated in this study.

In round III, the 12 research priority lists identified in round II were sent to the respondents to rate research priority similar to that in round II. However, as all participants agreed with the priority list, they did not need to rate again, and the comparison between the results of round II and round III was not necessarily presented. Therefore, the final research priorities in round III were totally the same as the research priorities in round II, which consisted of five themes in the rank order (1=nursing care quality, $2=$ management and leadership of nurse managers, $3=$ nursing image, 4=professional nurse competency, and 5=human resource management) in nursing management leadership, three themes (1=knowledge-specific domain, 2=the linkage between education and practice, and $3=$ nurse teacher workforce) in nursing education, and four themes (1=adult nursing concern, 2=patient safety, 3=public health concern, and 4=QoL) in nursing service (see Table 3).

\section{Discussion}

Findings of this study identified nursing research priorities in Vietnam, which were categorized into three groups, namely nursing management and leadership, nursing education, and nursing services. The top research priorities in each group were identified based 


\begin{tabular}{llrc}
\hline Rank & Priority & $M$ & SD \\
\hline \hline \multirow{3}{*}{$\begin{array}{lll}\text { Nursing management and leadership } \\
2\end{array}$} & Nursing care quality & 4.37 & 0.12 \\
2 & Management and leadership of nurse & 4.36 & 0.15 \\
& managers & & \\
3 & Nursing image & 4.21 & 0.15 \\
4 & Professional nurse competency & 4.16 & 0.03 \\
5 & Human resource management & 3.96 & 0.14 \\
& Nursing education & & \\
1 & Knowledge specific domain & 4.63 & 0.01 \\
2 & The linkage between education and practice & 4.53 & 0.06 \\
3 & Nurse teacher workforce & 4.00 & 0.04 \\
& Nursing service & & \\
1 & Adult nursing concern & 4.29 & 0.07 \\
2 & Patient safety & 4.29 & 0.14 \\
3 & Public health nursing concern & 4.25 & 0.09 \\
4 & Quality of life & 4.13 & 0.14 \\
\hline
\end{tabular}

Table 3. Top priorities in the category of nursing management and leadership, nursing education, and nursing service.

on the mean score rated by all participants. We discuss the research priorities in each group as follows.

\subsection{Nursing management and leadership}

\subsubsection{Theme 1. Nursing care quality}

Nurses are the biggest group of the health professionals who have a key role in providing best possible care for 24 hours and undertaking interprofessional coordination and integration, especially in the hospital setting. ${ }^{19}$ However, to ensure the quality of care, there are some research topics, which remain important to explore. It is explained in the following subthemes.

\subsubsection{Subtheme 1.1. Job description of nurses}

This topic remains important, as today the job description of nurses is the same although they have different backgrounds of educational levels in Vietnam.

\subsubsection{Subtheme 1.2. Standard of nursing care}

The standard of nursing care needs to be developed and updated to ensure to provide the best quality. All informants agreed that the standard of nursing care is important to guide nurses in their clinical practice in various settings and also specific nursing area for common diseases, and it can also be used as an objective tool to evaluate their performance.

\subsubsection{Subtheme 1.3. EBP}

This priority is likely to increase the intention and awareness of nurses in applying EBP. EBP is aimed to increase patient's health and safety. However, this study also emphasizes on the barriers to promoting EBP, as literature identified some barriers in doing EBP, such as time, workload pressure, lack of knowledge in research methodology, and lack of support and confidence in the research arena. ${ }^{20}$

\subsubsection{Subtheme 1.4. Nursing care delivery}

This priority is related to the organization of care delivery system and nurse staffing. However, this system is closely related to nurse-patient ratio and the need to compare which kind of nursing care delivery model is effective, as in the literature mentions so many models such as primary nursing model, team, functional model and any other innovative models. ${ }^{21}$

\subsubsection{Subtheme 1.5. Innovation in nursing}

In this study, we emphasize on technological innovations in nursing, as now we are living in the digital age, where technology has moved nurses away from manual ways to being advance workers in providing nursing care at the right time, in the right place, and for the right reasons.

\subsubsection{Subtheme 1.6. Nursing documentation}

In Vietnam, most of the nurses in the hospital setting are still using paper-based documentation, which may affect the quality of accuracy of documentation itself. Literature stated that nurses usually write in a repetitive manner, which may have less meaningful data and more inaccuracies. ${ }^{22}$

\subsubsection{Subtheme 1.7. Nurse attitude and awareness toward quality}

Attitude and awareness of nurses are important factors in providing nursing care. If their attitude and awareness are low, then nursing care quality will be low as well. ${ }^{23}$ However, there is lack of information about the awareness of nurses in understanding patients' expectations in regard to their care in Vietnam.

\subsubsection{Theme 2. Management leadership of nurse managers}

\subsubsection{Subtheme 2.1. Quality of leadership and management}

Strong nursing leadership and management are needed to create practice environments for both nurses and patients. Thus, the evaluation of nurse managers' competency and their leadership style is needed. 


\subsubsection{Subtheme 2.2. Supervision}

This priority is likely to evaluate the supervision model made by nurse managers as they have a role to supervise and manage their nurse staff. However, this supervision is based on the key performance indicators (KPIs); therefore, KPI standard is also needed to develop in Vietnam.

\subsubsection{Theme 3. Nursing image}

Image is part of a profession, which is the way profession appears to other disciplines and to the general public. ${ }^{24}$ It is necessary to explore the image of nurses to help nurses develop strategies to achieve a public image that reflects nursing professionalism. ${ }^{24}$

\subsubsection{Theme 4. Professional nurse competency}

\subsubsection{Subtheme 4.1. Standard competency of nurses}

The need for development of competency in this study is subjected to nurses. What we need to do is to develop and update the standard of nurses' competency based on the level of nurses, identify factors influencing their competency, and provide interventions to improve them.

\subsubsection{Theme 5. HRM}

\subsubsection{Subtheme 5.1. Nurse career}

Career ladder programs are established to reward clinical excellence. Nurse managers need to manage professional nurses so that they will achieve their career and job satisfaction.

\subsubsection{Subtheme 5.2. CPD}

This topic is closely related to nursing career plan, in which nurses have to continue professional development for their career. Nurse managers need to consider CPD when they allocate nursing resources in their units. We also emphasize the barriers to undertaking CPD, as a study mentioned that barriers to do CPD such as understaffing and time allocation may interfere with the work. ${ }^{25}$

\subsubsection{Subtheme 5.3. Work motivation for staff nurses}

As the profession needs to standby 24 hours in the hospital, nurses definitely need motivation to provide better care and cooperation. Understanding the motivation and the motives of nurses can improve job satisfaction, productivity, and quality of care. ${ }^{26}$

\subsubsection{Subtheme 5.4. Recruitment of nurse staff}

This is likely an important issue in Vietnam, as nursing shortage still exists. VNA needs to recruit more nurses. However, recruitment process is an important part of HRM, which is implemented with proper strategic planning. Understanding the recruitment process of nurses in each setting in Vietnam is necessary.

\subsection{Nursing education}

\subsubsection{Theme 1. Knowledge-specific domain}

\subsubsection{Subtheme 1.1. Quality of teaching learning}

This topic focuses on knowledge of nursing students, which is influenced by the quality of teaching and learning, which is a vital part of the quality of higher education. This is closely related to the competencies of teaching staff. High-quality learning is not possible without high-quality teaching. Thus, evaluation of the quality of teaching learning of nursing education is needed.

\subsubsection{Theme 2. The linkage between education and practice}

We realized that the gap between nursing education and nursing practice still exists. Thus, this topic becomes a research priority. Subthemes were identified as follows.

\subsubsection{Subtheme 2.1. Curriculum model}

To bridge the gap between education and practice, all participants agreed that it should start from the curriculum and its evaluation whether it supports the integration of education and practice.

\subsubsection{Subtheme 2.2. Learning outcome}

To measure the students' outcome, knowledge and skill should be assessed. Grading and objective structured clinical examination are often used as a comprehensive measurement methodology for assessing student-learning outcomes. ${ }^{27}$

\subsubsection{Subtheme 2.3. Educational model}

This priority likely emphasizes on student-centered learning by putting responsibility of the learning path in the hands of students, which aims to develop learner 
autonomy and independence. We need to evaluate the results of student-centered learning in the nursing institutions in Vietnam.

\subsubsection{Theme 3. Nurse teacher workforce}

\subsubsection{Subtheme 3.1. Teacher-student ratio}

This issue remains important because teacher-student ratio affects the teaching and learning process and the learning outcomes.

\subsubsection{Subtheme 3.2. Faculty competency}

This topic is essential to ensure that the quality of teaching learning is brought by the qualified faculty members. Their competency warrants consideration for the student's learning outcome.

\subsection{Nursing service}

\subsubsection{Theme 1. Adult nursing concern}

\subsubsection{Subtheme 1.1. Wound care management}

Clinically, the patients have changed over time, who are presenting complex wounds as a result of multiple comorbidities due to longevity and advances in medicine. Thus, nurses are demanded to understand how wound dressings work.

\subsubsection{Subtheme 1.2. Pain management}

The main symptom that leads individuals to seek healthcare is pain, existing whenever the experiencing person says it does. Thus, effective pain management is fundamental to the quality of care. However, the pain is complex and subjective in nature; a comprehensive understanding of pain is necessary for nurses.

\subsubsection{Subtheme 1.3. Management of end-of-life or palliative care}

This topic remains important as palliative care or endof-life care aims to improve the patient's QoL through symptom management.

\subsubsection{Theme 2. Patient safety}

\subsubsection{Subtheme 2.1. Developing and evaluating nursing-sensitive outcome indicators}

Nursing-sensitive indicators are valid and reliable measures that reflect the structure, processes, and outcomes of nursing care and clinical practice in the hospital unit setting. ${ }^{28}$

\subsubsection{Theme 3. Public health nursing concern}

\subsubsection{Subtheme 3.1. Community strategies to reduce health risks}

The burden of chronic diseases such as heart disease, stroke, diabetes, cancer, obesity, and arthritis in Vietnam is increasing. In fact, these diseases affect quality of people's lives and their families. This priority emphasizes on the early detection of diseases and developing strategies to reduce health risks.

\subsubsection{Subtheme 3.2. Family care, caregiving, and preventive mental health}

This topic is likely to focus on nurses in preparing the competency of family caregivers in providing physical, psychological, social, and spiritual support for their families. The preparation should include health education and training and follow-up programs.

\subsubsection{Subtheme 3.3. Culturally appropriate lifestyle intervention for health promotion, primary and secondary prevention, risk reduction, and health-seeking behavior across the lifespan}

This topic is likely to focus on culturally based lifestyle intervention for the community. It has been highly recognized that culturally based prevention programs can facilitate the adoption and maintenance of healthy behaviors in the community. ${ }^{29}$

\subsubsection{Theme 4. QoL}

\subsubsection{Subtheme 4.1. QoL of patients}

This topic is likely to focus on patients with chronic diseases to increase their QoL. QoL is a subjective perception of an individual about his/her position in life. As a nurse, we need to understand the needs of each individual and to have a similar understanding of a patients' QoL between nurses and their patients.

\subsubsection{Subtheme 4.2. Quality of working life of nurses}

Nurses as the key front of healthcare providers should have a good quality of working life in order to motivate them to providing better quality of care. Nurse managers should pay attention to the nurses' working life.

In this study, some of the priority research topics generated by respondents were very broad (e.g., "public health and adult nursing"). Although these were helpful in identifying general topics of concern and may be indicative of the enormous need for research in these topics, they may be less helpful in generating specific 
research topics for clinical nurse researchers in the region. Although we have no reason to think that our participants were not representative of the region, it is possible that some important representatives were missed. Future study needs to validate and compare these results with a bigger sample size and scope in Vietnam.

\section{Conclusions}

The purpose of this study was to identify nursing research priorities in Vietnam. The majority of priorities were well aligned and concentrated on nursing management, nursing education, and nursing service. For next future research, it ought to discover strategies to address these prerequisites. Funding for forthcoming research should be coherent with these priorities, which were identified by experts. This study generated a set of research directions that should be viewed as a positive step toward the goals of health care system and professional nursing. As such, this study offers fundamental insight into areas of furthermost significance

\section{References}

1. Aungsuroch Y. Enhancing Nursing Service and Nursing Education in ASEAN. Thailand: Chulalongkorn University; 2016.

2. National Nursing \& Nursing Education Taskforce. Priorities for Nursing and Midwifery Research in Australia. Australia: Australian Health Ministers' Advisory Council; 2006.

3. Bäck-Pettersson S, Hermansson E, Sernert N, Björkelund C. Research priorities in nursing-a Delphi study among Swedish nurses. J Clin Nurs. 2008;17:2221-2231.

4. Thompson CJ. Research priorities for nursing education: application to clinical nurse specialist education. Clin Nurse Spec. 2017;31:285-288.

5. Brenner M, Hilliard C, Regan G, et al. Research priorities for children's nursing in Ireland: a Delphi study. J Pediatr Nurs. 2014;29:301-308.

6. Dowding DW, Currie LM, Lawton R, et al. International priorities for research in nursing informatics for patient care. Stud Health Technol Inform. 2013;192:372-376.

7. Kang S, Ho TTT, Nguyen TAP. Capacity development in an undergraduate nursing program in Vietnam. Front Public Health. 2018;6:146.

8. Nguyen HC, Evers C, Marshall S. Accreditation of Viet Nam's higher education: achievements and challenges after a dozen years of development. Qual Assur Educ. 2017;25:475-488. for emphasis and funding as acknowledged by nurse research experts in Vietnam.

\section{Acknowledgments}

The authors acknowledge the Faculty of Nursing, Chulalongkorn University, Thailand, and Faculty of Nursing and Medical Technology, University of Medicine and Pharmacy, Ho Chi Minh City, Vietnam, for all valuable support.

\section{Ethical approval}

This study was approved by the Board of Ethics in Biomedical Research of the University of Medicine and Pharmacy, Ho Chi Minh City, with No. 08/UMP-BOARD on January 10,2017 . Written informed consent was obtained from all the experts.

\section{Conflicts of interest}

All contributing authors declare no conflicts of interest.
9. Phuong HLT, Simon JHE. Nursing education in Vietnam. Ann Bull Niigata Coll Nurs Educ Persp. 2016;5:2-9.

10. Phuong HT. Nursing service in Viet Nam. In: Aungsuroch $\mathrm{Y}$, ed. Enhancing Nursing Service and Nursing Education in ASEAN. Thailand: Chulalongkorn University; 2016.

11. Ha DT, Nuntaboot K. How nurses in hospital in Vietnam learn to improve their own nursing competency: an ethnographic study. J Nurs Care. 2016;5:368.

12. Hasson F, Keeney S, McKenna H. Research guidelines for the Delphi survey technique. J Adv Nurs. 2000;32:1008-1015.

13. Sun C, Dohrn J, Oweis A, et al. Delphi survey of clinical nursing and midwifery research priorities in the Eastern Mediterranean region. J Nurs Scholarsh. 2017;49:223-235.

14. Wilhelm WJ. Alchemy of the oracle: the Delphi technique. Delta Pi Epsilon. 2001;43:6-26.

15. Akins RB, Tolson H, Cole BR. Stability of response characteristics of a Delphi panel: application of bootstrap data expansion. BMC Med Res Methodol. 2005;5:37.

16. Hsieh HF, Shannon SE. Three approaches to qualitative content analysis. Qual Health Res. 2005;15:1277-1288.

17. Krippendorff K. Content Analysis: An Introduction to its Methodology. California: Sage; 2004. 
18. Kirkwood M, Wales A, Wilson A. A Delphi study to determine nursing research priorities in the North Glasgow University Hospitals NHS Trust and the corresponding evidence base. Health Info Libr J. 2003;20:53-58.

19. Twigg D, Attree M. Patient safety: committing to learn and acting to improve. Nurse Educ Today. 2014;34:159-161.

20. Taylor S, Allen D. Visions of evidence-based nursing practice. Nurs Res (through 2013). 2007;15:78.

21. Gunawan J. The Innovation of Nursing Care Delivery Model: A Hybrid Model. Thailand: Faculty of Nursing Chulalongkorn University; 2015.

22. Scruth EA. Quality nursing documentation in the medical record. Clin Nurse Spec. 2014;28:312-314.

23. Siverbo $\mathrm{K}$, Eriksson $\mathrm{H}$, Raharjo $\mathrm{H}$, et al. Attitudes toward quality improvement among healthcare professionals: lessons from a hospital-wide quality initiative. Int J Qual Serv Sci. 2014;6:203-212.

24. Finkelman A. Professional Nursing Concepts: Competencies for Quality Leadership. Massachusetts: Jones \& Bartlett Learning; 2017.
25. Katsikitis M, McAllister M, Sharman R, Raith $L$, Faithfull-Byrne A, Priaulx R. Continuing professional development in nursing in Australia: current awareness, practice and future directions. Contemp Nurse. 2013;45:33-45.

26. Hamouzadeh P, Moradkhani B, Sadeghifar J. Factors affecting on job motivation from the managers point of view in teaching hospitals affiliated to Urmia University of Medical Sciences in 2009. J Urmia Nurs Mid Fac. 2011;9: 15-22.

27. Rushforth HE. Objective structured clinical examination (OSCE): review of literature and implications for nursing education. Nurse Educ Today. 2007; 27:481-490.

28. Heslop L, Lu S. Nursing-sensitive indicators: a concept analysis. J Adv Nurs. 2014;70:2469-2482.

29. Murdoch-Flowers J, Tremblay M-C, Hovey R, et al. Understanding how Indigenous culturallybased interventions can improve participants' health in Canada. Health Prom Int. 2019;34(1): 154-165. 